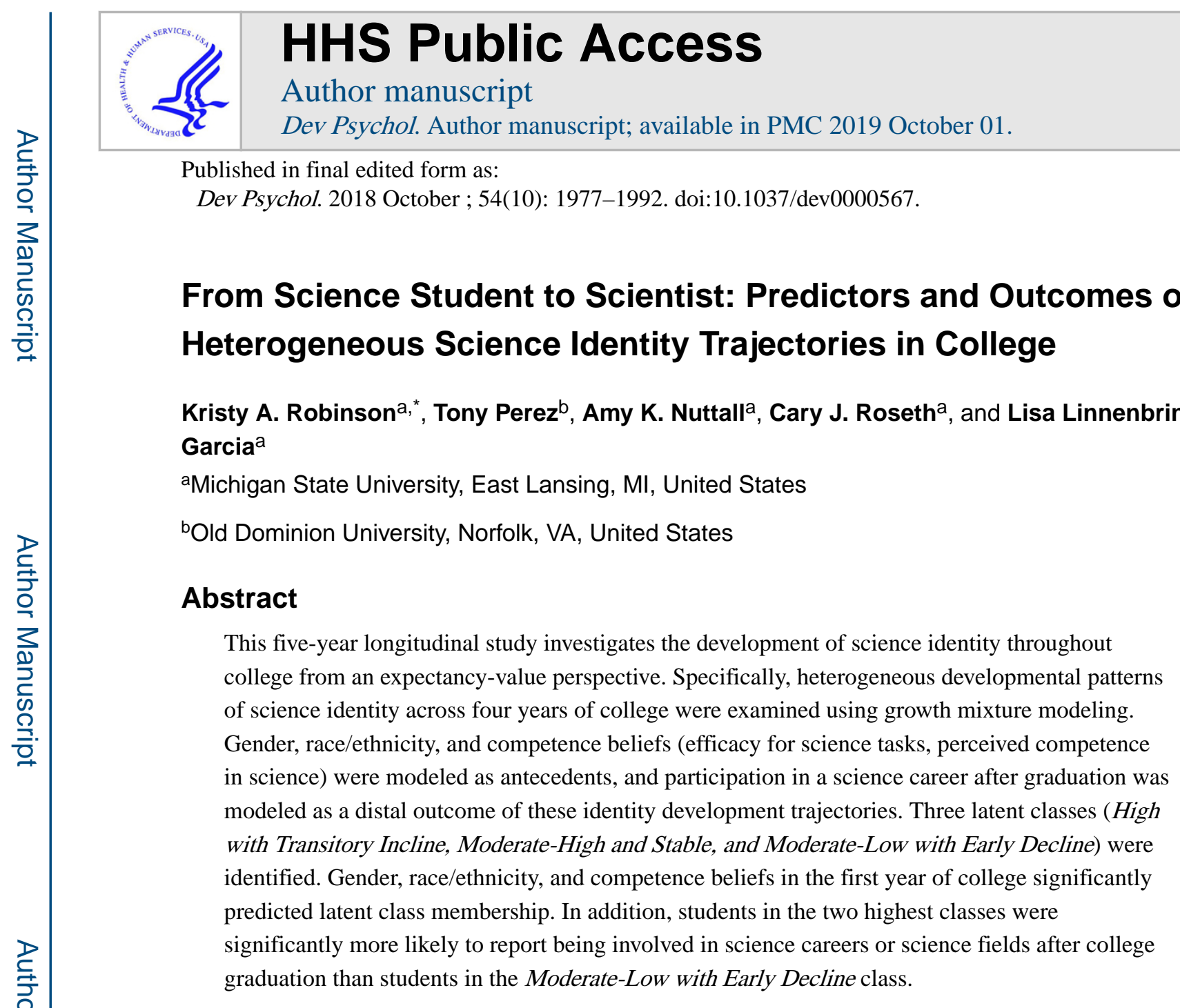

\title{
Keywords
}

science identity development; growth mixture modeling; expectancy-value; STEM persistence

\begin{abstract}
While college is a time of potentially volatile change in students' academic and professional identities (Côté, 2006; Eccles, 2009; Marcia, 1993; Roisman, Masten, Coatsworth, \& Tellegen, 2004; Waterman, 1993), few prior studies have examined developmental trajectories during these years. This gap in knowledge is especially problematic in science, technology, engineering, and math (STEM) domains where there is an acute need to expand and diversify the workforce (National Science and Technology Council, 2013). After all, many students start college with the intention of majoring in a STEM discipline and pursuing a STEM career, but a large proportion "leak" out of the STEM pipeline, particularly students who are traditionally underrepresented in science fields (National Science Board, 2016; Koenig, 2009; Myers \& Pavel, 2011; Penner, 2015). Different patterns of identity development may help to explain why this occurs.
\end{abstract}

Correspondence concerning this article should be addressed to: Kristy A. Robinson, Department of Counseling, Educational Psychology \& Special Education, Erickson Hall, Michigan State University, 620 Farm Lane, East Lansing, MI 48824. Phone: 385-321-0373, robi1004@msu.edu.

${ }^{*}$ The authors gratefully acknowledge You-kyung Lee for her helpful feedback on drafts of this manuscript. 
Extant work on identity development in STEM (e.g., Hernandez, Schultz, Estrada, Woodcock, \& Chance, 2013) generally considers changes in identity on the average, without considering whether developmental patterns vary among individuals. However, there is likely to be a great deal of heterogeneity in identity trajectories, given the variety of barriers that some students may face during college such as stereotype threat and the often competitive climate of introductory STEM courses (Murphy, Steele, \& Gross, 2007; Seymour \& Hewitt, 1997). Thus, a person-oriented developmental approach may be needed to account for heterogeneous patterns of science identity development. Moreover, theory and prior research suggest that students' competence beliefs are important in identity development (Eccles 2009; Chemers, Zurbriggen, Syed, Goza, \& Bearman, 2011; Robnett, Chemers, \& Zurbriggen, 2015), and that identity development processes have important implications for career outcomes (Eccles, 2009; Estrada, Woodcock, Hernandez, \& Schultz, 2011; Hernandez et al., 2013; Woodcock, Hernandez, Estrada, \& Schultz, 2012). However, there is little empirical research investigating these claims, especially longitudinal research that follows traditional college students (i.e., student who enter college directly from high school) from the start of college until after graduation.

In the current study, we use an expectancy-value theory perspective to investigate science identity development among a diverse population of traditional college students who begin college with a focus in science. Specifically, we aim to (1) identify and describe varying science identity trajectories across four years of college, (2) consider predictors of these science identity trajectories, and (3) examine how science identity trajectories predict postgraduation participation in science careers.

\section{Conceptualization of Identity}

Students who begin college intending to pursue science often engage in academic pursuits and career preparation activities that have the potential to solidify or destabilize academic and career identities (Eccles, 2009; Waterman, 1993). Contemporary Expectancy-Value Theory (Eccles, 2009) posits that an individual's expectancies for success and appraisals of value for a task or domain (i.e., task value) are the most proximal predictors of academic and occupational choices (Eccles et al., 1983). Task value is conceptualized as multifaceted, with individuals valuing tasks or domains for multiple reasons including the personal importance of a task or domain because of its relevance to their personal and collective (or social) identities (i.e., attainment value; Eccles, 2009). Attainment value in particular is conceptualized as a central, defining component of an individual's personal and collective identities.

Expectancy-value theory's conceptualization of identity is similar to the self-theories or schemas as conceptualized by Markus and Nurius (1986). It is also has much in common with identity commitments that define Marcia's (1993) foreclosed (i.e., committed to an identity that is valued by important others) and achieved (i.e., committed to an identity after personal exploration) identity statuses, although Eccles does not differentiate between commitments made through differing exploration processes as Marcia does in the egoidentity status model. An expectancy-value view of identity is also similar to the concept of 'identification with commitment' (e.g., embracing and integrating commitments into one's 
sense of self) in Luyckx and colleagues' dual-cycle model of identity formation (Luyckx, Goossens, Soenens, \& Beyers, 2006; Schwartz, Zamboanga, Luyckx, Meca, \& Ritchie, 2013). However, the focus in expectancy-value theory is on salient identity contents (e.g., importance of a particular identity), with academic and occupational choices viewed as potential enactments of such identity contents. Thus, if majoring in science and pursuing a science career is an enactment of one's science identity, then one should have high expectancies for success in science, high attainment value for science, and be more likely to have a career in science after graduation.

\section{Development of Science Identity During College}

According to expectancy-value theory, the importance, salience, and contents of one's identities represent dynamic processes that change over time in response to information gleaned from the environment, from introspection, and through experience (Eccles, 2009). This means that students who enter college highly valuing a science identity may continue to explore the importance of this and other identities over time. It also means that students may encounter periods of identity instability as a result of destabilizing events, such as receiving a poor grade in a course or experiencing stereotype threat (cf. Luyckx et al., 2006). However, much of the identity literature has focused on identity processes broadly, either examining identity processes in general (e.g. exploration and commitment; Luyckx, Teppers, Klimstra, \& Rassart, 2014) or in relation to broad domains such as education and friendship (e.g. Klimstra et al., 2010). Thus, the present student contributes to this literature by focusing specifically on identity in science and examining different patterns of change over time.

Despite the potential importance of college for stabilizing or destabilizing science identity, there exists little longitudinal research examining the development of science identity during this time. In one relevant study, Hernandez and colleagues (2013) found that science identity ${ }^{1}$, examined over three years in a sample of college students from underrepresented ethnic and racial groups, was relatively stable, suggesting that there are very few changes in science identity towards the latter half of college. This finding aligns with other research reporting slight, but statistically significant change in vocational identity across three time points during high school (Negru-Subtirica, Pop, \& Crocetti, 2015). Taking a personoriented approach, Musu-Gillette, Wigfield, Harring, and Eccles (2015) also examined whether there were multiple, distinct trajectories of value ${ }^{2}$ for math during adolescence and early adulthood. Results indicated that mathematics value declined rapidly for some students (fast decline), slowly for others (slow decline), and remained relatively stable, though lower overall (low steady) for a third class of students. However, given their broader developmental focus, Musu-Gillette and colleagues only included one measurement point in college, which makes it difficult to make claims about developmental trajectories within college.

\footnotetext{
${ }^{1}$ Science identity was conceptualized somewhat differently in terms of role orientation (e.g., a composite of identity beliefs related to belonging, interest, and self-categorization as a scientist; see Estrada et al., 2011 for a more detailed discussion) rather than identityrelated attainment value.

2 Value was conceptualized in terms of both utility and attainment value, and attainment value was assessed in terms of broad personal importance. Thus, the measure of value used does not fully align with Eccles' (2009) conceptualization of identity-related importance.
} 
One important implication of Musu-Gillette et al.'s (2015) findings is that solely examining one average trajectory may mask sub-group differences in identity development. Thus, using a person-oriented approach to complement variable-oriented research on science identity development may provide insight into the nature of the construct and advance theoretical understanding. For practice, this approach may also indicate whether interventions to support science identity should be administered to all students or only to subgroups of students.

\section{Predictors of Science Identity Trajectories}

In addition to describing heterogeneity in developmental trajectories, further research is also needed to illuminate the processes through which science identity can be supported or destabilized. According to expectancy-value theory, competence beliefs, derived from appraisals of success or failure in the domain, are important predictors of the value one places on a domain (Wigfield \& Cambria, 2010), including identity-related attainment value. Specifically, a student's perceived failure on domain-specific tasks can lead that student to devalue his or her identity and seek other options, while a student's apparent success may lead the student to seek out future opportunities to re-engage. Citing a large body of research linking task-specific competence beliefs to behavior, Eccles (2009) further posits that identity formation processes may act as a mediator between competence beliefs and behavioral choices. Thus, students who pursue science when beginning college may be at risk for lower identity appraisals over time if they are unsure about their science abilities.

While there are a variety of relevant competence beliefs, we focus on two common types: perceived competence, or students' beliefs in their ability to learn content in a given domain, and self-efficacy, which is students' confidence in their ability to successfully complete specific tasks (Schunk \& Pajares, 2005). We conceptualize perceived competence in terms of students' general beliefs about their ability to learn and do academic work in science courses and self-efficacy as students' beliefs about their ability to successfully complete specific tasks related to the scientific process (e.g., generate a hypothesis, analyze/interpret data). Both ability beliefs may influence students' science identity beliefs: self-efficacy via experiences that inform students' beliefs about their ability to perform scientific tasks, and perceived competence via students' beliefs that they can successfully navigate the academic challenges associated with pursuing a scientific career. But self-efficacy may be a more relevant predictor of science identity because it pertains to "authentic" scientific skills used by scientists (at least in terms of how we conceptualize self-efficacy here), as opposed to academic skills that may or may not be useful in a science career. Students who lack confidence in their ability to pass a test in a science course may or may not view this as relevant to their identities as scientists, whereas lack of confidence in one's ability to form and test a scientific hypothesis may directly inform appraisals of science identity. Supporting this view, prior research indicates that self-efficacy mediates the relation between research experiences and science identity, both concurrently (Chemers et al., 2011) and longitudinally (Robnett et al., 2015). However, no prior research investigates perceived competence as a predictor of science identity trajectories, nor does it assess both self-efficacy and perceived competence as predictors. Thus, the present study extends prior work by testing whether 
both of these competence beliefs predict membership in different science identity trajectories.

In addition to competence beliefs, gender as well as race and ethnicity may predict differences in college students' developing science identities. Women and students from underrepresented ethnic/racial groups (e.g., African American, Hispanic/Latino) may face additional barriers to identifying with science, as evidenced by low representation in STEM fields and a lower likelihood of completing degrees in STEM in the United States (National Science Board, 2016; Koenig, 2009; Myers \& Pavel, 2011). However, empirical support for this claim is mixed. Within the math domain, for example, gender predicted different trajectories of value-related identity change among adolescents in some studies (Nagy et al., 2008; Watt, 2004), but not others (Musu-Gillette et al., 2015). Importantly, this prior work did not consider science specifically nor did it follow students throughout college. And, there is little, if any, research that examines whether racial/ethnic minority students experience declines in science-related identity throughout college in comparison to majority groups. Thus, while there is research suggesting possible mechanisms for disidentification in science by both women and racial and ethnic minorities (e.g., stereotype threat, Cokley, 2002; Osborne, 1995; 1997), we know very little about whether underrepresented groups in the sciences actually experience distinct patterns of science identity development longitudinally throughout college relative to male and Caucasian or Asian students. As such, it is critical to first understand whether women and racial/ethnic minorities are more likely to experience steeper declines in identity throughout college, before attempting to further investigate the particular contextual and psychological elements that may be associated with varying patterns of identity development during college among gender and racial/ethnic groups traditionally underrepresented in STEM fields.

\section{Science Identity Trajectories as Predictors of Science Careers}

As a defining component of identity, attainment value provides a framework for organizing overall self-perceptions, worldviews, and behavior (Eccles, 2009; Kaplan \& Flum, 2012; Oyserman, 2015; Rosenberg, 1979). Thus, the more a student values science as a part of his or her identity, the more he or she also self-evaluates through the lens of a scientist, thinks like a scientist, and makes choices that are congruent with being a scientist. Developmentally, it follows that students reporting high science identity should also be more likely to choose and achieve science careers after graduation. However, these links between identity and behavior have not yet been fully investigated, as most studies integrating identity and motivation constructs as important predictors of college science students' retention have been limited by cross-sectional designs (e.g., Andersen \& Ward, 2013; Chemers et al., 2011; Hazari, Sonnert, Sadler, \& Shanahan, 2010). One exception to this pattern is the study by Estrada and colleagues (2011), who found that science identity in a sample of underrepresented minority students was a powerful predictor of science career intentions and behavioral involvement in science (e.g., independent research and graduate school attendance) assessed one year later. Likewise, in two subsequent studies using a similar sample, Woodcock et al. (2012) found that science identity predicted underrepresented minority college students' intentions to pursue a scientific research career (one year later), and Hernandez and colleagues (2013) found that science identity 
trajectories positively correlated with stability in mastery goals, which was in turn a significant positive predictor of undergraduate GPA.

Extant research focused specifically on value is also relevant to the relation between identity beliefs and STEM persistence. For instance, Musu-Gillette and colleagues (2015) found that adolescents whose value for mathematics declined more rapidly were less likely to choose a math-intensive major in college. Focusing specifically on identity development in science, other research has found that students who engaged in identity exploration reported higher value for science and lower perceived costs associated with pursuing a science major than students who chose a major based on others' expectations (Perez, Cromley, \& Kaplan, 2014). Importantly, commitment to a career identity after exploration was related to persistence intentions via students' value for science. That is, students who reported higher value (including attainment value conceptualized as personal importance) and lower costs associated with pursuing STEM fields reported lower intentions to leave science.

\section{Present Study}

In summary, extant literature provides some information about the development of science identity, as well as its predictors and implications for involvement in science careers, but also leaves important questions unexamined. For example, prior studies used varied conceptualizations of science identity, often combining numerous identity facets into one measure (e.g., Chemers et al., 2011; Estrada et al., 2011). Additionally, while two prior studies considered how identity trajectories predict subsequent persistence-related outcomes (Hernandez et al., 2013; Musu-Gillete et al., 2015), only one has followed students after graduation to assess whether or not they were involved in science fields (Estrada et al., 2011), which is perhaps the most important outcome of interest to science educators and policy makers. Accordingly, the current study extends theory and prior research by examining heterogeneous change trajectories in traditional college students' science identities over the entirety of the undergraduate leaky STEM pipeline, from the beginning of college through one year after graduation. Three research questions guided the work:

1. Are there multiple patterns (or latent classes) of science identity development during college?

2. How do gender, race/ethnicity, perceived competence, and self-efficacy predict science identity class membership?

3. Do differential science identity trajectories (class membership) predict science career outcomes after college graduation?

Based on prior research identifying heterogeneous developmental patterns of value for academic subjects (e.g., Musu-Gillette et al., 2015), we expected to find multiple classes of development in science identity. Given that these were students enrolled in courses for science majors, we expected that the science identity intercept for at least some classes would be relatively high. We also expected that some students would exhibit declines in science identity over time (Marcia, 1993) and others would report stable or increasing patterns of science identity over time, presumably as a result of different affirming or destabilizing experiences. We also tested for non-linear change based on the assumption that 
identity development is dynamic and on-going and therefore not necessarily linear (Eccles, 2009). We did not have specific hypotheses about the number of classes, particularly as testing quadratic growth trajectories in addition to linear growth expanded the possible growth patterns.

As posited by expectancy-value theory (Eccles, 2009) and prior research showing strong relations between self-efficacy and science identity (Chemers et al., 2011; Estrada et al., 2011), we hypothesized that both competence beliefs (self-efficacy for science tasks, academic perceived competence in science) would predict class membership, with higher competence beliefs in the first year predicting membership in classes with higher initial science identity and either growth or stability in science identity during college. Given its relevance to future science careers, we expected that science self-efficacy would explain unique variance when controlling for perceived competence. We also expected that perceived competence would explain significant, unique variance in class membership because of the importance of academic success for pursuing science careers.

We also examined whether women and underrepresented minority students were more likely to belong to identity trajectories characterized by declines in science identity. The assumption was that these groups are underrepresented in STEM and would therefore encounter different opportunities and barriers for developing their identities as scientists. Attrition from science is disproportionately higher for women and racial/ethnic minority students (National Science Foundation, 2015), and prior research provides evidence that domain-specific values and competence beliefs vary by gender and race/ethnicity (Cokley, 2002; Gaspard et al., 2015; Jacobs, Lanza, Osgood, Eccles, \& Wigfield, 2002; Nagy et al., 2008). Therefore, we hypothesized that female students and students from underrepresented racial/ethnic groups would be more likely to exhibit declines in science identity over time.

Finally, in alignment with theory (Eccles, 2009) and prior research (e.g., Chemers et al., 2011; Estrada et al., 2011; Musu-Gillette et al., 2015; Woodcock et al., 2012), we expected that science identity class membership would differentially predict participants' involvement in science careers or fields after college. We hypothesized that students with relatively high and stable or increasing science identity would be more likely to be involved in science careers than students for whom science identity decreased over time and/or whose levels of science identity were initially low.

\section{Method}

\section{Participants and Procedure}

Data for the current study were collected as part of an ongoing intervention study at an elite university in the United States. The study, titled "Self-Generated Research Experiences to Support Biomedical/Behavioral Research Careers," was approved by the Institutional Review Board at Lisa Linnenbrink-Garcia's former and current institutions (IRB Nos. A0166 and x16-881e). Students who participated in the intervention $(n=197)$ were excluded from our analyses, because the intervention may have impacted the constructs examined in the current study. Using a longitudinal design that prospectively assessed students across five years following a three-year original enrollment period, data collection 
began during fall of participants' freshman year (2010, 2011, or 2012) and continued annually through the year after graduation. Therefore, our data collection period spanned seven years. Participants were recruited from freshman chemistry courses required for science majors. With the permission of course instructors, we visited each chemistry course to describe the study and invite participation. Students aged 18 and over who were in their first year of college were eligible to participate. Those who were not yet $18(n=56)$ at the time of recruitment were invited to participate after turning 18 . Of the 2,581 students enrolled in the recruitment courses, $75 \%(n=1,934)$ agreed to participate in the study. Students provided informed consent and completed paper surveys in class, receiving $\$ 10$ for participation.

From this larger sample of students who completed the first-year baseline survey, a longitudinal comparison group was randomly selected from those who did not participate in the intervention, with stratification to oversample women and students from underrepresented ethnic and racial groups. ${ }^{3}$ The selected comparison group, consisting of 1,023 participants, was invited annually to take follow-up surveys via email during spring semester of their sophomore, junior, and senior years as well as eight months postgraduation, resulting in 5 waves of data. Of those invited to take follow-up surveys, $49 \%$ ( $n$ $=506)$ responded to the sophomore (T2) survey, $45 \%(n=456)$ responded to the junior year (T3) survey, $46 \%(n=475)$ responded to the senior year (T4) survey, and 47\% $(n=483)$ responded to the postgraduation survey (T5). Students who did not complete one or more of the follow-up surveys were still invited to participate in subsequent follow-up surveys. College dropout was quite rare in this sample (4\%), and participants were invited to complete follow-up surveys whether or not they dropped out of college.

The final sample for the present study included the entire comparison group sample of 1,023 undergraduate students (58\% female; 25\% White, $43 \%$ Asian, $13 \%$ African American, $11 \%$ Hispanic/Latino, $8 \%$ multi-racial/other). Results of missing data analyses are provided in the results section.

\section{Measures}

Science identity-Science identity was assessed annually each of the four years of college using a 4-item self-report scale adapted from two scales: a science identity scale developed by Pugh, Linnenbrink-Garcia, Koskey, Stewart, and Manzey (2009) and an attainment value scale developed by Conley (2012). The four items measure individual appraisals of the personal importance or value of science to one's identity ( $a=.83-.90)$, for example: "Being involved in science is a key part of who I am." Students rated items on a Likert-type scale ranging from 1 to 5 , with $1=$ strongly disagree and $5=$ strongly agree.

Competence beliefs-Self-efficacy for science tasks was measured in the first year using a six-item scale ( $a=.84)$, adapted by Estrada et al. (2011) from Chemers et al. (2011) assessing students' confidence in their ability to complete scientific tasks. An example item

\footnotetext{
${ }^{3}$ The intervention group had a larger proportion of women and underrepresented ethnic and racial minority groups than the student population; thus, we also over sampled women and racial/ethnic minority groups in the comparison group in an attempt to match the intervention sample.
} 
read, "I am confident that I can generate a research question to answer." Perceived competence for science coursework, or students' confidence in their ability to succeed at academic work in science, was measured in the first year using a five-item scale (Midgley et al., 2000; $a$ =.87). A sample item for this scale is, "Even if the work in science is hard, I can learn it." Items for both scales were rated on a 5-point Likert-type scale ( $1=$ strongly disagree, $5=$ strongly agree).

Science involvement-To assess students' participation in science careers or graduate programs after college graduation, participants responded to a self-report item collected in the spring following graduation. The question asked, "Do you consider yourself to be involved in a science-related career or field?" Following the question, science-related careers or fields were defined for the participant: "A science-related career is one that is based on scientific knowledge or principles, uses scientific methodology and techniques, and/or engages in scientific research." Participants could choose 1 = "Yes, I'm involved in a traditional science career/field (e.g., work in a lab, science research analyst/consultant, continuing my education in a science career (e.g., medical school, $\mathrm{PhD}$ program in science, etc.))", 2 = "Somewhat, my work is related to science but is not in a traditional field (e.g., science writer, investment advisor in biotech, drug regulatory affairs)", or 3 = "Definitely not". Categories 1 and 2 were collapsed for the current study to create a dichotomous measure, with 1 indicating involvement in a science-related career or field and 0 indicating no involvement in science.

\section{Data Analytic Strategy}

All analyses were conducted using Mplus Version 8 (Muthén \& Muthén, 1998-2017) and missing data were handled using full information maximum likelihood (FIML) estimation. Prior to fitting growth models, preliminary analyses included descriptive statistics, correlations, and examining individual trajectory plots to inform the selection of plausible models for examination (Ram \& Grimm, 2009).

Latent growth model-First, latent growth modeling, which represents a one-class growth mixture model, was used to select a baseline model for GMM (Masyn, 2013; Ram \& Grimm, 2009). Intercept-only (no growth), linear, and quadratic models were fit to the full sample to find the best-fitting representation of change for the overall sample.

Growth mixture models-Growth mixture modeling (GMM) was used to identify classes of participants based on observed heterogeneity in patterns of change (Nylund, Asparouhov, \& Muthén, 2007). Rather than relying on a single growth curve model, which assumes all participants belong to a single population, or on multi-group models defined by observed group membership, GMM was used to classify heterogeneity in patterns of change. Bayesian Information Criterion (BIC) was used to select the class solution, with smaller values of BIC indicating better fit, because simulation studies demonstrate the utility of the BIC in GMM (Nylund et al., 2007). The theoretical interpretability of class solutions was also considered in the selection of the final classes (Grimm \& Ram, 2009b; Nylund et al., 2007). 
The introduction of predictors (termed covariates in the GMM literature) and distal outcomes of class membership can be approached in a number of ways. One approach, the one-step method, involves adding covariates or distal outcomes directly to the GMM; however, adding these variables to a GMM provides additional information that influences estimation, often changing the class solution. This can make interpretation difficult, particularly when researchers aim to understand covariates as predictors of class membership (Vermunt, 2010). Another approach involves a 3-step procedure: after the GMM is specified (Step 1), each case is assigned to the most likely class based on probabilities of latent class membership (Step 2). Class membership is then used as a categorical variable which can be modeled as a predictor or an outcome (Step 3). However, because this method treats latent class membership as known, standard errors and estimates of model parameters are biased (Vermunt, 2010).

In the current study, we used an updated 3-step approach (Asparouhov \& Muthén, 2014) implemented in the Mplus software (Muthén \& Muthén, 1998-2017) to introduce covariates (gender, race/ethnicity, self-efficacy, and perceived competence) and a distal outcome (postgraduation science involvement) to the GMM. After estimating the GMM, this approach is similar to the earlier 3-step approach in that it assigns each case to the most likely class in Step 2, then regresses the most likely class on predictor variables (or distal outcomes on class). However, the updated approach improves upon the one-step approach by taking into account the uncertainty of classification in the second step using logit probabilities that have been shown to result in less biased estimates than the original 3-step procedure while maintaining a stable class solution for the GMM and interpretable coefficients for predictors and outcomes of class membership (Asparouhov \& Muthén, 2014). The command R3STEP was used for covariates, and the DCATEGORICAL command was used for the distal outcome, as recommended by Muthén \& Muthén (1998-2017; see also Asparouhov \& Muthén, 2012; Vermunt, 2010).

\section{Results}

\section{Preliminary Analyses}

Correlations and descriptive statistics-Table 1 displays correlations and descriptive statistics for each study variable. Science identity at all time points was significantly positively correlated with self-efficacy and perceived competence at Time 1, and selfefficacy and perceived competence were also positively correlated. As expected, repeated measures of science identity were also positively correlated over time and means of science identity were relatively stable over time. Overall, $77 \%$ of participants reported being involved in a science-related career or field after graduation.

Missing data-To address the assumptions for full information maximum likelihood estimation (FIML), we examined patterns of missing data in relation to study variables. Study recruitment (e.g., invitations to complete follow-up surveys) was randomly selected with follow-up invitations regardless of prior participation, and the amount of missing data at each time point was within the expected range (52-57\%). In addition, participants with any missing data were compared to subjects with complete data on demographic variables, 
initial competence beliefs, and initial science identity. Students with missing data did not significantly differ from students with complete data on first-generation college student status $\left[\chi^{2}(2)=.314, p=0.86\right]$, but the two groups did differ significantly with respect to membership in an underrepresented ethnic/racial minority group $\left[\chi^{2}(1)=10.55, p<.01\right]$ and gender $\left[\chi^{2}(1)=15.83, p<.001\right]$. Those with complete data were more likely to be female and White or Asian/Asian American. The MANOVA comparing year 1 perceived competence, self-efficacy, and science identity was not significant, Wilks' $\lambda(3,1014)=$ $0.99, p=.06, \eta^{2}=0.01$.

Confirmatory factor analyses-Confirmatory factor analyses (CFAs) for Time 1 perceived competence and self-efficacy indicated that the two-factor model fit the data well, $\chi^{2}(43)=191.966$, RMSEA $=.06, \mathrm{CFI}=.97, \mathrm{TLI}=.96$, providing evidence that participants differentiated self-efficacy for scientific tasks from perceived competence for science coursework in their responses. Below, we describe the measurement model for science identity.

\section{Second-Order Growth Model}

Measurement invariance-In order to make inferences about change over time, it is necessary to first establish evidence that the same construct is being measured over time. Observed change over time can then be attributed to true change rather than change in the meaning of the construct over time (Widaman \& Reise, 1997). Measurement invariance over four time points for the first-order common factor model for science identity was evaluated by successively fitting configural, weak, strong, and strict invariance models. The configural model constrained the factor structure to be the same across time. Weak invariance was specified by additionally constraining factor loadings to be equal across time, and strong invariance additionally assumed equal observed intercepts over time. Lastly, the strict invariance model constrained residual variances for observed factor indicators over time. Model comparisons resulted in less than .01 change in CFI between models (see Table 2; Cheung \& Rensvold, 2002). Therefore, the strict invariance model of science identity, with invariant factor loadings, intercepts, and unique factor variances across time (Widaman, Ferrer, \& Conger, 2010), fit the data well and provided evidence that the same construct was measured over time. This model was used as the first-order measurement model for science identity in subsequent analyses.

We also conducted tests of group invariance by gender and race/ethnicity assuming time invariance within groups (i.e., factor loadings, intercepts, and residual variances were constrained to be equal over time). Similar to the test of measurement invariance over time, we fit configural, weak, strong, and strict invariance models including all four time points of science identity with parameters successively constrained to be equal across groups. As displayed in Table 2, results showed evidence of strict measurement invariance in science identity across gender and race/ethnicity groups.

Second-order latent growth curve model-With strict invariance constraints imposed on the first-order measurement model, science identity trajectories were modeled as secondorder latent factors first with an intercept-only (no growth) model, a linear growth model, 
and finally a quadratic model. Model fit was acceptable for the intercept-only model, $\chi^{2}$ $(139)=638.12, \mathrm{RMSEA}=.059, \mathrm{CFI}=.914, \mathrm{TLI}=.926$. The linear model, $\chi^{2}(136)=$ $532.49, \mathrm{RMSEA}=.053, \mathrm{CFI}=.932, \mathrm{TLI}=.940$, appeared to fit the data better than the intercept-only model, with a difference in CFI of $>.01$. The quadratic model, $\chi^{2}(132)=$ $491.28, \mathrm{RMSEA}=.052, \mathrm{CFI}=.939, \mathrm{TLI}=.944$, appeared to fit the data similarly to the linear model, but the quadratic factor was non-significant $(M=-.005, S E=.01, p=.69)$. Importantly, for the intercept-only, linear, and quadratic models, the addition of gender and race/ethnicity as auxiliary variables in FIML estimation resulted in no changes to fit indices or model parameters.

For the entire sample, these findings suggest that the linear model offered the most parsimonious fit to the data, describing initial mean science identity at $3.74(S E=0.04, p<$. 001), a slight, non-significant negative linear slope of $-.03(S E=.01, p=.06)$, and significant estimated variation in the intercept $\left(\sigma^{2}=0.39, S E=0.04, p<.001\right)$ and slope $\left(\sigma^{2}\right.$ $=0.04, S E=.01, p<.001)$. However, for the GMM analyses, we tested both linear and quadratic models because the two unconditional models fit similarly and quadratic patterns could be identified for subgroups in the sample, even if the overall pattern is linear.

Growth mixture model selection-The next step in our analyses was to examine heterogeneity in developmental trajectories of science identity among the students in our sample using GMM. A series of 2-, 3-, and 4-class linear and quadratic models were specified and compared to a 1-class baseline model, successively freeing between-class equality constraints in order to examine increasingly complex models (Grimm \& Ram, 2009a). In order to test heterogeneity in the initial level and slope of change in science identity across classes, we successively freed the means, variances, and covariances of the intercept and slope factors to be class-specific (e.g., vary across classes; see Table 3, 4, and 5 for the 2-, 3-, and 4-class models, respectively). In addition, we also successively freed residual variances, factor intercepts, and factor loadings of the first-order science identity factors to be class-specific in order to assess measurement invariance across classes, avoid over-extraction of classes, and minimize bias in parameter estimates (Enders \& Tofighi, 2008). We selected a three-class solution with class-specific means of the intercept, linear slope, and quadratic slope factors, and class-specific residual variances of observed items; all other parameters were class-invariant (see Table 4, Model 10). This model had the lowest $\mathrm{BIC}$ value, was interpretable, and aligned with theoretical expectations. Classification quality was acceptable, with average latent class probabilities for most likely latent class memberships greater than .80. Therefore, we identified three classes that differed in terms of mean level, rate of change, and unexplained variance.

Table 6 displays parameter estimates for each class, and Figure 1 displays model-implied trajectories of science identity for each class. Sample sizes and proportions are based on most likely class memberships for each case. In one class (High with Transitory Incline; $n=$ $404 ; 40 \%$ of sample), science identity was initially high, with a positive linear slope and a negative quadratic slope. In other words, these students reported high science identity at the beginning and end of college, which then increased and decreased slightly across college. The second class (Moderate-High and Stable; $n=513 ; 50 \%$ of sample) was characterized by relatively lower initial science identity and non-significant mean linear and quadratic slopes. 
These students reported moderately high science identity in their first year and relative stability in their beliefs throughout college. The third class (Moderate-Low with Early Decline; $n=106 ; 10 \%$ of sample) reported relatively low levels of initial science identity, with a sharply decreasing linear slope and a positive quadratic slope. This class was characterized by lower science identity in the first year, which then decreased sharply from the first to second years then leveled off between the third and fourth years. Non-overlapping confidence intervals confirmed that the intercepts differed significantly across the three classes. The intercept in the High with Transitory Incline class, $M=4.12,95 \%$ CI [3.97, 4.27], was significantly higher than the intercept of the Moderate-High and Stable class, $M=$ $3.61,95 \%$ CI $[3.38,3.84]$, and both were significantly higher than the intercept of the Moderate-Low with Early Decline class $M=2.93,95 \%$ CI [2.62, 3.25].

\section{Predictors of Class Membership}

Following the selection of the 3-class GMM, auxiliary variables were added to the model as predictors of class membership using the updated 3-step method in Mplus (Asparouhov \& Muthén, 2014). Composite scores for perceived competence and self-efficacy were calculated by averaging the items due to specification limitations with regards to the inclusion of latent variables in the 3-step approach as implemented in Mplus. Gender (male $=0$, female $=1$ ), membership in an underrepresented racial/ethnic group (African American, Hispanic/Latino, or Native American = 1, White or Asian/Asian American =0), selfefficacy, and perceived competence were modeled as predictors of class membership. Multinomial logistic regression coefficients and odds ratios for each pairwise comparison are presented below and each coefficient can be interpreted as the difference in log odds of being in a class (vs. the reference class) associated with a 1-unit difference in the predictor variable, controlling for the other predictors.

The coefficients for gender indicate that women were nearly two times more likely than men to be in the Moderate-High and Stable class compared to the High with Transitory Incline class $(b=0.64, p<.01$, odds ratio $=1.90)$. There was no evidence of gender differences in the likelihood of being in the Moderate-Low with Early Decline class compared to the High with Transitory Incline class $(b=0.52, p=.09$, odds ratio $=1.68)$ or in the likelihood of being in the Moderate-High and Stable vs. the Moderate-Low with Early Decline class ( $b=$ $-0.12, p=.72$, odds ratio $=.89$ ).

Coefficients for membership in an underrepresented racial/ethnic group (URM) indicate that African American, Native American, and Hispanic students were more than two times as likely as racial/ethnic majority students to be in the Moderate-Low with Early Decline class compared to the High with Transitory Incline class ( $b=0.75, p<.05$, odds ratio $=2.12$ ). There was no evidence of racial/ethnic group differences in the likelihood of being in the Moderate-Low with Early Decline compared to the Moderate-High and Stable class ( $b=$ $0.48, p=.15$, odds ratio $=1.62$ ), nor was there any evidence of differences in the likelihood of being in the Moderate-High and Stable compared to the High with Transitory Incline class $(b=0.28, p=.23$, odds ratio $=1.32)$.

Higher self-efficacy predicted a greater likelihood of being in the High with Transitory Incline class $(b=0.92, p<.001$, odds ratio $=2.51)$ or the Moderate-High and Stable class ( $b$ 
$=0.92, p<.001$, odds ratio $=2.51)$ compared to the Moderate-Low with Early Decline class. Self-efficacy was not a significant predictor of membership in the High with Transitory Incline class vs. the Moderate-High and Stable class $(b=0.001, p=.59$, odds ratio $=1.00)$. These coefficients indicate that self-efficacy was an important predictor of whether students were most likely to be in either of the two relatively high and stable classes of science identity versus the low and declining class.

Higher perceived competence predicted a greater likelihood of being in the High with Transitory Incline class vs. the Moderate-Low with Early Decline class $(b=0.56, p<.05$, odds ratio $=1.75$ ), but was not a significant predictor of being in the High with Transitory Incline class vs. the Moderate-High and Stable class $(b=0.29, p=.08$, odds ratio $=1.34)$ or of membership in the Moderate-High and Stable vs. Moderate Low with Early Decline classes $(b=0.28, p=.24$, odds ratio $=1.32)$. These coefficients indicate that variation in perceived competence was an important discriminator between low and high science identity trajectories, but was not predictive of less extreme differences (i.e., Moderate-High vs. High class or Moderate-High vs. Low).

\section{Class Membership and Science Career Outcomes}

Finally, we tested whether science identity class membership predicted participants' involvement in science careers after graduation. This model did not include predictors of class membership, as the 3-step method does not allow for both predictor and outcome auxiliary variables to be modeled simultaneously. Class membership was significantly associated with involvement in a science career or field after graduation, $\chi^{2}(2)=60.50, p$ $<.001$. Specifically, $88.7 \%$ of students in the High with Transitory Incline class and $83.3 \%$ of participants in the Moderate-High and Stable class reported being in a science-related career or field after graduation, compared to $27.2 \%$ of those in the Moderate-Low with Early Decline class. Follow-up chi-square comparisons indicated that there was no significant difference in the likelihood of High with Transitory Incline and Moderate-High and Stable students being in a science career after graduation, $\chi^{2}(1)=1.19, p=.28$, whereas those in the Moderate-Low with Early Decline class were less likely to be in a science career compared to both the High with Transitory Incline, $\chi^{2}(1)=58.66, p<.001$, and the Moderate-High and Stable classes, $\chi^{2}(1)=49.23, p<.001$.

\section{Discussion}

Using expectancy-value theory as a framework, the current study examined the development of science identity during college, a key developmental period for career-related identities. Results showed evidence of three latent developmental trajectories that were differentially associated with gender, race/ethnicity, academic perceived competence, and science selfefficacy. The trajectories also differentially predicted participation in a science-related career after graduation. By examining changes in science identity across four years of college, a key time period of the "leaky pipeline" in science career pursuit, and tracking students beyond graduation to examine post-college career outcomes, our results provide critical information about science identity development during college and its consequences for science career persistence after graduation. 
We identified three latent classes that exhibited qualitative differences in the development of science identity across four years. We labeled one High with Transitory Incline because it was characterized by high science identity in the first year with a slight increase followed by a slight decrease in science identity during the four years of college, but overall reflected very high levels throughout college. Another class was labeled Moderate-High and Stable because it was characterized by moderately high science identity in the first year with little to no evidence of change over four years. The third class was labeled Moderate-Low with Early Decline because it reflected relatively low science identity in the first year with a sharp decrease, followed by a less dramatic decrease in the final two years. These findings suggest that students belonging to the High with Transitory Incline and Moderate-High and Stable groups remained strongly identified with the field throughout their undergraduate career, while the Moderate-Low with Early Decline group disidentified with science early in college. In fact, the magnitude of decrease in science identity corresponded to an average change from "neutral" to "disagree" responses to science identity items in later years. The identification of multiple patterns of science identity development extends prior research showing multiple developmental trajectories for literacy value (Archambault, Eccles, \& Vida, 2010) and math value (Musu-Gillette et al., 2015) among adolescents and early college students by focusing on science identity across all four years of college.

These findings lend support to the idea that identities are relatively stable once commitments are made (Eccles, 2009), with value remaining high and relatively stable for two of the three latent classes. Our results also suggest that consistently high science identity was the most commonly reported experience among the students in our sample, with $50 \%$ of participants classified in the Moderate-High and Stable class and 40\% in the High with Transitory Incline class. The high occurrence of these patterns is likely a result of our initial sampling procedure and focus on the leaky pipeline among prospective science majors; students who were less strongly identified with science might have delayed enrollment in the required introductory chemistry course until a later semester. Given the heavy emphasis on preprofessional goals (e.g., pre-med, pre-law) at this elite university, it is also possible that our sample included students who were more strongly committed (cf. Luyckx et al., 2006) to a particular career path than might be observed in a broader population of college students.

At the same time, however, our finding of a class experiencing initially lower science identity followed by a sharp decline is also consistent with the idea that college is a time of potentially volatile changes in identity as students confront new experiences and challenges (Eccles, 2009; Waterman, 1993). Following Marcia (1993), the Moderate-Low with Early Decline class may also represent a class of students in moratorium, with students beginning their college years unsure about their commitment to science and experiencing subsequent instability in their science identity. While this experience represents only $10 \%$ of the sample, these findings suggest that identities can be re-evaluated and change rather dramatically for some students, perhaps as a result of changing circumstances (e.g., beginning college; see also Luyckx, Schwartz, Goossens, Beyers, \& Missotten, 2011), hostile environments, or gender/race-based discrimination in STEM fields.

Looking at predictors of class membership, the findings regarding race/ethnicity also indicate that students from underrepresented racial/ethnic groups were more likely to report 
moderate to low levels of science identity that decreased throughout college. Additionally, both women and URMs were least likely to be in the class with the highest levels of science identity. This aligns with our hypotheses and with prior research indicating that Black, Hispanic/Latino, and female students encounter unique difficulties while navigating White-, Asian-, and male-dominated science fields (Seymour \& Hewitt, 1997). However, the results did not indicate that women were more likely to be in the Moderate-Low with Early Decline class vs. the other two classes, which was unexpected. According to the expectancy-value model, values for science are shaped by sociocultural factors, and these factors lead to differences in both value and expectancies for success across gender and racial/ethnic groups. As such, it is likely that observed gender and racial/ethnic differences may be a result of discrimination and inequality (Wong, Eccles, \& Sameroff, 2003) as well as differences in critical psychological processes related to discrimination and stereotypes about science as the domain of men and individuals of Caucasian or Asian descent. Although not measured in this study, it seems likely that key psychological processes such as stereotype threat (Murphy et al., 2007), belonging threat (Walton \& Cohen, 2007), or perceptions that science is incongruent with gender or racial/ethnic roles (Cheryan, Plaut, Davies, \& Steele, 2009; Diekman, Brown, Johnston, \& Clark, 2010; Settles, Jellison, \& Pratt-Hyatt, 2009) may have accounted for these gender and racial/ethnic differences in class membership. Indeed, the sciences are still dominated by men, White students, and Asian students at this university. For example, in the first-year chemistry courses where participants were recruited for the current study, only $33 \%$ of faculty were women.

Our research also provides support for theorized relations among competence beliefs and identity processes (Eccles, 2009). As we expected and in alignment with prior research exhibiting relations between competence beliefs and science identity (Eccles, 2009; Chemers et al., 2011; Robnett et al., 2015), both self-efficacy and perceived competence were significant predictors of class membership. Students who felt more confident in their ability to succeed at academic tasks, form and test hypotheses, use scientific equipment, and form conclusions using the scientific method were more likely to report higher, more stable science identity throughout college. In addition, the two competence beliefs exhibited differential patterns of relations to science identity trajectories: while self-efficacy appeared to be an important factor for differentiating the highest two trajectories from the Moderate-

Low science identity trajectory, perceived competence was only associated with membership in the highest pattern of science identity relative to the lowest pattern. This indicates that while both competence beliefs may be important factors supporting science identity among those who are unsure of their commitment, variation in self-efficacy better discriminates the Moderate-Low with Early Decline class from the Moderate-High and Stable class. This is particularly significant considering that it may be easier to shift students from moderately low to moderately high levels of science identity than to very high levels, with important implications for career attainment. This suggests a need for expectancy-value theorists to differentially examine competence beliefs for academic and career-related tasks, as they appear to be differentially related to identity development.

Consistent with our hypotheses and with prior research showing strong relations between science identity and career outcomes (Chemers et al., 2011; Estrada et al., 2011; Hernandez et al., 2013), we also found that class membership was a significant predictor of participants' 
reported involvement in science fields after graduation. Students in the two classes with higher identity were more likely to be involved in science careers after graduation than students in the Moderate-Low with Early Decline class. This is in accord with expectancyvalue conceptualizations of identity and suggests that for students who enter college aiming for science careers, attrition from science fields may be explained in part by lower initial levels of and declines in science identity. Even among well-prepared students at an elite university with numerous supports for retention, lower initial levels and declines in science identity significantly decreased the likelihood of post-graduation involvement in science. Similarly, lower competence beliefs at the beginning of college may put students at risk for lower initial identities and greater instability in their science identities. Among a sample of first-year undergraduates enrolled in chemistry courses at an elite university, it is not necessarily surprising that most students had higher initial science identity and remained stable over time. However, the $10 \%$ of students in the Moderate-Low with Early Decline class may be important to target for intervention, as they show early interest in science but are lost along the way. An important question is whether contextual barriers explain this pattern and whether it is possible to develop or use existing interventions to mitigate the loss of these students from science. We discuss this further in the Implications section below.

Finally, our focus on identity-related conceptions of attainment value also supports and refines expectancy-value theory. While earlier expectancy-value conceptualizations of attainment value (e.g., Wigfield \& Eccles, 2000; Wigfield et al., 1997) characterized attainment value as personal importance broadly (e.g., "For me, being good at math is important"), more recent conceptualizations (Conley, 2012; Eccles, 2009) emphasize the importance of a task or domain to the individual's identity. Recent research by Gaspard and colleagues (2015) examined two types of attainment value for math: personal importance and broad importance of high achievement, the former relating more closely to identity. They found that this differentiation accurately reflected distinct types of value for academic subjects and revealed differential relations to other constructs, such as gender and other types of value. Indeed, tasks may be important to individuals for a variety of reasons, just as students can perceive tasks to be costly along several dimensions (Eccles, 1983). Greater precision in conceptualizing and measuring value constructs can refine our understanding of the phenomena and its relations to important correlates. The current study helps to clarify this issue by focusing on identity-related attainment value specifically and over time.

\section{Implications for Supporting Persistence in Science}

In addition to implications for theory and research, the current study has numerous practical implications for supporting persistence in science. First, significant relations between class membership and post-graduation involvement in science suggest that identity development is an important predictor of science careers and is worth investigating as a possible point of intervention for increasing persistence. Thus, efforts at broadening and diversifying the workforce in science fields should aim to support not only necessary motivation, skills, and knowledge, but also students' science identity development, and more particularly sustained high value for their identities as scientists. 
Importantly, our identification of multiple classes suggests a need for differential supports for identity development, as only $10 \%$ of students reported declines in science identity during college. In addition, while students from racial/ethnic minority groups were more than twice as likely as their White and Asian peers to be in the Moderate-Low class vs. the High class, and women were almost twice as likely as men to be in the Moderate-High class vs. the High class, our data suggests that what matters for science career outcomes is not whether students have high or moderately high science identity, but rather whether they start college with lower science identity and experience declines. Lastly, it is important to note that students may have begun college with different levels of science identity and it was those with lower initial levels who experienced declines over time. This suggests a multipronged approach may be necessary for supporting science identity, and ultimately, persistence in science careers by supporting both initial levels and stability throughout college.

Given our findings that both perceived competence and self-efficacy predicted whether students were most likely to be classified into the Moderate-Low with Early Decline class, one potential mechanism for supporting scientific identity development is through precollege interventions that target students' confidence in their ability to complete scientific and academic tasks. This is encouraging, particularly as self-efficacy is fairly malleable over short periods of time (Bong \& Skaalvik, 2003), and can be supported via mastery experiences, vicarious experiences, social persuasion, and affective states (Bandura, 1986; Usher, 2009). Thus, we see the need for future research aimed at helping high school students begin college with greater confidence in their science abilities.

It may also be possible to target science identity more directly either before students enter college or as they first begin to take challenging science coursework. Relevance interventions (Hulleman \& Harackiewicz, 2009), which directly target task value, could be most appropriately used in high school or the first year of college to help students connect science to their lives and so increase initial science identity. However, even when students begin college with high value and competence in science, low perceived belonging, discrimination, or other experiences relevant to their personal identities may prompt students to devalue the importance of science to their identities (Steele, 1997). Designing more equitable environments, particularly to minimize discriminatory practices and subtle cues that may activate belonging threat or stereotype threat (e.g., Murphy et al., 2007), should be a primary concern of educational institutions. In addition, values affirmation interventions (Cohen, Garcia, Apfel, \& Master, 2006) and belonging interventions (Walton \& Cohen, 2007) could be used after students begin college to prevent students from construing academic setbacks as reflections of their abilities or belonging within science, potentially preventing sharp declines in science identity.

More broadly, involvement in STEM enrichment programs may be an additional way to support science identity directly, as those who strongly identify with both a personal identity and a scientific identity appear to maintain stronger commitments to science than those who perceive their personal and scientific identities to be incompatible (Settles, 2004). There is some evidence that mentoring or other targeted science programs can minimize stereotype threat and influence feelings of belonging in science (Carlone \& Johnson, 2007; Merolla, 
Serpe, Stryker, \& Schultz, 2012; Merolla \& Serpe, 2013). These, along with the relevance, belonging, and values affirmation interventions mentioned above, may directly support science identity development among those most at risk for declines and help to reduce the racial/ethnic gap in pursuing science career attainment (National Science Foundation, 2015).

\section{Limitations and Future Directions}

A few limitations should be considered when interpreting the results. First, our sample consisted of students at an elite, private university who may be more highly qualified for science training and careers. Our sampling procedure also targeted only those students who were enrolled in chemistry courses required for natural science majors in their first semester, which may have excluded students who delayed taking a required chemistry course in in their first semester because they were unsure about whether they wanted to pursue a science degree. Thus, replication is needed in other university settings and among other groups of students. As a balance to this limitation, however, it is important to note that our findings signal that scientific identity is a key factor for retention in science even among students who are well qualified and receive high-quality training. Indeed, the $10 \%$ of these highlyqualified students in the Moderate-Low with Early Decline class suggest that interventions could prove useful even in this sample. Furthermore, our sample was comprised of "traditional" college students, and these findings may not generalize to non-traditional college students. For example, an older undergraduate student with a family may start college more committed to a science identity but also may face more barriers due to their family responsibilities.

Second, replication of these results in additional samples is also an important direction for future work for statistical reasons. As with any longitudinal study, our study had some missing data and it is possible that results may be biased due to the overrepresentation of female, White, and Asian students among those with data at all five time points. Replication is therefore necessary to understand heterogeneous developmental trajectories of science identity groups with higher representation of males and those from racial/ethnic groups that are underrepresented in science fields. In addition, models estimating class-specific variance parameters of initial levels and change factors did not converge. Instead, our model assumed that variances were the same across classes. This is a limitation of the data, and replication with a new data set may provide sufficient resolution to allow for estimating class-specific variances of these parameters. As is true with any application of growth mixture modeling, replication is important considering the data-driven nature of GMM.

A third limitation is that we only measured science identity once per year. While this measurement interval aligns with the theorized slow pace of change in identity constructs, research with shorter intervals of measurement is needed to test this assumption. This may be particularly relevant for identity salience, which has been manipulated in lab settings (LeBoeuf, Shafir, \& Bayuk, 2010) and may be a more appropriate construct on which to intervene in support of identity development given its potentially greater malleability.

Fourth, our study was also potentially limited by the self-report nature of the science career outcome measure. While participants' reports of whether they are involved in science careers are likely to be accurate (e.g., Estrada et al., 2011), particularly considering that we 
clearly defined what we meant by science careers when posing the question to participants, it is also possible that participants still had varied perceptions of what constitutes a science field. For instance, some who are involved in social science fields (e.g., psychology) may consider themselves to be involved in science while others may not. Future research should combine self-report and objective measures of science career involvement, when possible, in order to assess and limit error in examining relations between science identity trajectories and career outcomes.

Lastly, a key future direction for increasing understanding of how science identity develops should involve directly examining experiences that facilitate or act as barriers to identity development in science (e.g., Estrada, Hernandez, \& Schultz, 2018). Our focus on psychological and demographic predictors does not provide empirical evidence of the specific experiences leading to between-student differences. Thus, it is important to more closely examine the mechanisms by which contextual influences lead to differences in science identity. Such research could provide evidence both about the barriers students experience as well as ways to overcome these barriers through direct support for students' psychological development and more broad-based institutional changes to the design of programs and courses.

\section{Conclusion}

A strong STEM workforce is vital to the health of our society. For students who enter college aiming for science careers, attrition from science may be partially explained by both lower initial levels and greater instability in science identity over time. Our study aimed to describe heterogeneity in developmental trajectories of science identity from an expectancyvalue perspective across four years of college, and to examine relations among these trajectories with first-year competence beliefs, gender, race/ethnicity, and post-graduation science careers. As hypothesized, we found latent classes of students with differential trajectories in science identity, and these trajectories were related to gender, race/ethnicity, and first-year competence beliefs as well as to career outcomes after college.

The findings from this five-year longitudinal study underscore the importance of understanding and supporting high initial levels and stability in science identity over time for traditional college students and also considering identity development before college. Furthermore, though our results indicate that a disproportionate number of underrepresented minority students report lower initial levels and declines in science identity throughout college, these declines could possibly be buffered by institutional supports for self-efficacy to perform scientific tasks and academic perceived competence prior to entry into college or during the first year. These findings contribute essential understanding of how science identity develops and also provide insight into the future design of interventions aimed at broadening participation in science fields. In short, becoming a scientist appears to involve more than cultivating skills and knowledge; students who also come to think of themselves as scientists may be best equipped to achieve success in science. 


\section{References}

Andersen L, Ward TJ. Expectancy-value models for the STEM persistence plans of ninth-grade, highability students: A comparison between Black, Hispanic, and White students. Science Education. 2013; 98:216-242. DOI: 10.1002/sce.21092

Archambault I, Eccles JS, Vida MN. Ability self-concepts and subjective value in literacy: Joint trajectories from grades 1 through 12. Journal of Educational Psychology. 2010; 102:804-816. DOI: $10.1037 / \mathrm{a} 0021075$

Asparouhov T, Muthén BO. Auxiliary variables in mixture modeling: Three-step approaches using Mplus. Structural Equation Modeling: A Multidisciplinary Journal. 2014; 21:329-341. DOI: 10.1080/10705511.2014.915181

Bandura A. Social foundations of thought and action. Englewood Cliffs, NJ: Prentice Hall; 1986.

Bong M, Skaalvik EM. Academic self-concept and self-efficacy: How different are they really? Educational Psychology Review. 2003; 15:1-40. DOI: 10.1023/A:1021302408382

Carlone HB, Johnson A. Understanding the science experiences of successful women of color: Science identity as an analytic lens. Journal of Research in Science Teaching. 2007; 44:1187-1218. DOI: 10.1002/tea.20237

Chemers MM, Zurbriggen EL, Syed M, Goza BK, Bearman S. The role of efficacy and identity in science career commitment among underrepresented minority students. Journal of Social Issues. 2011; 67:469-491. DOI: 10.1111/j.1540-4560.2011.01710.x

Cheryan S, Plaut VC, Davies PG, Steele CM. Ambient belonging: How stereotypical cues impact gender participation in computer science. Journal of Personality and Social Psychology. 2009; 97:1045-1060. DOI: 10.1037/a0016239 [PubMed: 19968418]

Cheung GW, Rensvold RB. Evaluating goodness-of-fit indexes for testing measurement invariance. Structural Equation Modeling: A Multidisciplinary Journal. 2002; 9:233-255. DOI: 10.1207/ S15328007SEM0902_5

Cohen GL, Garcia J, Apfel N, Master A. Reducing the racial achievement gap: A social-psychological intervention. Science. 2006; 313:1307-1310. DOI: 10.1126/science.1128317 [PubMed: 16946074]

Cokley KO. Ethnicity, gender, and academic self-concept: A preliminary examination of academic disidentification and implications for psychologists. Cultural Diversity and Ethnic Minority Psychology. 2002; 8:378-388. DOI: 10.1037//1099-9809.8.4.378 [PubMed: 12416323]

Conley AM. Patterns of motivation beliefs: Combining achievement goal and expectancy-value perspectives. Journal of Educational Psychology. 2012; 104:32-47. DOI: 10.1037/a0026042

Côté JE. Young adulthood as an institutionalized moratorium: Risks and benefits to identity formation. In: Arnett JJ, Tanner JL, editorsYoung adulthood in America: Coming of age in the 21st century. Washington, DC: American Psychological Association; 2006. 85-116.

Diekman AB, Brown ER, Johnston AM, Clark EK. Seeking congruity between goals and roles: A new look at why women opt out of science, technology, engineering, and mathematics careers. Psychological Science. 2010; 21:1051-1057. doi:IO.I177/0956797610377342. [PubMed: 20631322]

Eccles JS. Expectancies, values, and academic behavior. In: Spence JT, editorAchievement and achievement motivation. San Francisco, CA: Freeman; 1983. 75-146.

Eccles J. Who am I and what am I going to do with my life? Personal and collective identities as motivators of action. Educational Psychologist. 2009; 44:78-79. DOI: 10.1080/00461520902832368

Enders CK, Tofighi D. The impact of misspecifying class-specific residual variances in growth mixture models. Structural Equation Modeling: A Multidisciplinary Journal. 2008; 15:75-95. DOI: $10.1080 / 10705510701758281$

Estrada M, Hernandez PR, Schultz PW. A longitudinal study of how quality mentorship and research experience integrate underrepresented minorities into STEM careers. CBE-Life Sciences Education. 2018; 17:1-13. DOI: 10.1187/cbe.17-04-0066

Estrada M, Woodcock A, Hernandez PR, Schultz PW. Toward a model of social influence that explains minority student integration into the scientific community. Journal of Educational Psychology. 2011; 103:206-222. DOI: 10.1037/a0020743 [PubMed: 21552374] 
Gaspard H, Dicke AL, Flunger B, Schreier B, Häfner I, Trautwein U, Nagengast B. More value through greater differentiation: Gender differences in value beliefs about math. Journal of Educational Psychology. 2015; 107:663-677. DOI: 10.1037/edu0000003

Grimm KJ, Ram N. A second-order growth mixture model for developmental research. Research in Human Development. 2009a; 6:121-143. DOI: 10.1080/15427600902911221

Grimm KJ, Ram N. Non-linear growth models in Mplus and SAS. Structural Equation Modeling. 2009b; 16:676-701. DOI: 10.1080/10705510903206055 [PubMed: 23882134]

Hazari Z, Sonnert G, Sadler PM, Shanahan MC. Connecting high school physics experiences, outcome expectations, physics identity, and physics career choice: A gender study. Journal of Research in Science Teaching. 2010; 47:978-1003. DOI: 10.1002/tea.20363

Hernandez PR, Schultz PW, Estrada M, Woodcock A, Chance RC. Sustaining optimal motivation: A longitudinal analysis of interventions to broaden participation of underrepresented students in STEM. Journal of Educational Psychology. 2013; 105:89-107. DOI: 10.1037/a0029691

Hulleman CS, Harackiewicz JM. Promoting interest and performance in high school science classes. Science. 2009; 326:1410-1412. DOI: 10.1126/science.1178712 [PubMed: 19965759]

Jacobs JE, Lanza S, Osgood W, Eccles JS, Wigfield A. Changes in children's self-competence and values: Gender and domain differences across grades one through twelve. Child Development. 2002; 73:509-527. DOI: 10.1111/1467-8624.00421 [PubMed: 11949906]

Kaplan A, Flum H. Identity formation in educational settings: A critical focus for education in the $21 \mathrm{st}$ century. Contemporary Educational Psychology. 2012; 37:171-175. DOI: 10.1016/j.cedpsych. 2012.01.005

Klimstra TA, Luyckx K, Hale WW, Frijns T, van Lier PAC. Short-term fluctuations in identity: Introducing a micro-level approach to identity formation. Journal of Personality and Social Psychology. 2010; 99:191-202. DOI: 10.1037/a0019584 [PubMed: 20565195]

Koenig R. Minority retention rates in science are a sore spot for most universities. Science. 2009; 324:1386-1387. DOI: 10.1126/science.324_1386a

LeBoeuf RA, Shafir E, Bayuk JB. The conflicting choices of alternate selves. Organizational Behavior and Human Decision Processes. 2010; 111:48-61. DOI: 10.1016/j.obhdp.2009.08.004

Luyckx K, Goossens L, Soenens B, Beyers W. Unpacking commitment and exploration: Preliminary validation of an integrative model of late adolescent identity formation. Journal of Adolescence. 2006; 29:361-378. DOI: 10.1016/j.adolescence.2005.03.008 [PubMed: 15878619]

Luyckx K, Schwartz SJ, Goossens L, Beyers W, Missotten L. Processes of personal identity formation and evaluation. In: Schwartz SJ, Luyckx K, Vignoles VL, editorsHandbook of identity theory and research: Structure and processes. New York: Springer; 2011. 77-98.

Luyckx K, Teppers E, Klimstra TA, Rassart J. Identity processes and personality traits and types in adolescence: Directionality of effects and developmental trajectories. Developmental Psychology. 2014; 50:2144-2153. DOI: 10.1037/a0037256 [PubMed: 24956298]

Marcia JE. The status of the statuses: Research review. In: Marcia JE, Waterman AS, Matteson DR, Archer SL, Orlofsky JL, editorsEgo identity: A handbook for psychosocial research. New York, NY: Springer-Verlag; 1993. 22-41.

Markus H, Nurius P. Possible selves. American Psychologist. 1986; 41:954-969. DOI: 10.1037/0003-066X.41.9.954

Masyn KE. Latent class analysis and finite mixture modeling. In: Little TD, editorThe Oxford Handbook of Quantitative Methods. New York, NY: Oxford University Press; 2013. 551-611.

Merolla DM, Serpe RT, Stryker S, Schultz PW. Structural precursors to identity processes: The role of proximate social structures. Social Psychology Quarterly. 2012; 75:149-172. DOI: $10.1177 / 0190272511436352$

Merolla DM, Serpe RT. STEM enrichment programs and graduate school matriculation: the role of science identity salience. Social Psychology of Education. 2013; 16:575-597. DOI: 10.1007/ s11218-013-9233-7 [PubMed: 24578606]

Midgley C, Maehr ML, Hruda LZ, Anderman E, Anderman L, Freeman KE, ... Urdan T. Manual for the Patterns of Adaptive Learning Scales (PALS). Ann Arbor, MI: University of Michigan; 2000. 
Murphy MC, Steele CM, Gross JJ. How situational cues affect women in math, science, and engineering settings. Psychological Science. 2007; 18:879-885. DOI: 10.1111/j. 1467-9280.2007.01995.x [PubMed: 17894605]

Musu-Gillette LE, Wigfield A, Harring JR, Eccles JS. Trajectories of change in students' self-concepts of ability and values in math and college major choice. Educational Research and Evaluation. 2015; 21:343-370. DOI: 10.1080/13803611.2015.1057161

Muthén LK, Muthén BO. Mplus User's Guide, Eighth Edition. Los Angeles, CA: Muthén \& Muthén; 1998-2017.

Myers CB, Pavel DM. Underrepresented students in STEM: The transition from undergraduate to graduate programs. Journal of Diversity in Higher Education. 2011; 4:90-105. DOI: 10.1037/ a0021679

Nagy G, Garrett JL, Trautwein U, Cortina KS, Baumert J, Eccles JS. The development of students' mathematics self-concept in relation to gender: Different countries, different trajectories? Journal of Research on Adolescence. 2008; 20:482-506. DOI: 10.1111/j.1532-7795.2010.00644.x

National Science and Technology Council. Federal Science, Technology, Engineering, and Mathematics (STEM) Education 5-year Strategic Plan. 2013. Retrieved January 29, 2015. (http:// www.whitehouse.gov/sites/default/files/microsites/ostp/stem_stratplan_2013.pdf)

National Science Board. Science and Engineering Indicators 2016. Arlington, VA: National Science Foundation; 2016. (NSB 2016-01)

National Science Foundation. Special Report NSF 15-311. Arlington, VA: 2015. Women, minorities, and persons with disabilities in science and engineering. Available at http:/www.nsf.gov/statistics/ wmpd/

Negru-Subtirica O, Pop EI, Crocetti E. Developmental trajectories and reciprocal associations between career adaptability and vocational identity: A three-wave longitudinal study with adolescents. Journal of Vocational Behavior. 2015; 88:131-142. DOI: 10.1016/j.jvb.2015.03.004

Nylund KL, Asparouhov T, Muthén BO. Deciding on the number of classes in latent class analysis and growth mixture modeling: A Monte Carlo simulation study. Structural Equation Modeling: A Multidisciplinary Journal. 2007; 14:535-569. DOI: 10.1080/10705510701575396

Osborne JW. Academics, self-esteem, and race: A look at the underlying assumptions of the disidentification hypothesis. Personality and Social Psychology Bulletin. 1995; 21:449-455. DOI: $10.1177 / 0146167295215003$

Osborne JW. Race and academic disidentification. Journal of Educational Psychology. 1997; 89:728735. DOI: $10.1037 / 0022-0663.89 .4 .728$

Oyserman D. Identity-based motivation. In: Scott R, Kosslyn S, editorsEmerging trends in the social and behavioral sciences: An interdisciplinary, searchable, and linkable resource. Hoboken, NJ: John Wiley \& Sons; 2015. 1-11.

Penner AM. Gender inequality in science. Science. 2015; 347:234-35. DOI: 10.1126/science.aaa3781 [PubMed: 25593174]

Perez T, Cromley JG, Kaplan A. The role of identity development, values, and costs in college STEM retention. Journal of Educational Psychology. 2014; 106:315-329. DOI: 10.1037/a0034027

Pugh K, Linnenbrink-Garcia L, Koskey KLK, Stewart VC, Manzey C. Motivation, learning, and transformative experience: A study of deep engagement in science. Science Education. 2009; 94:1-28. DOI: $10.1002 /$ sce. 20344

Ram N, Grimm KJ. Growth mixture modeling: A method for identifying differences in longitudinal change among unobserved groups. International Journal of Behavioral Development. 2009; 33:565-576. DOI: 10.1177/0165025409343765 [PubMed: 23885133]

Robnett RD, Chemers MM, Zurbriggen EL. Longitudinal associations among undergraduates' research experience, self-efficacy, and identity. Journal of Research in Science Teaching. 2015; 52:847-867. DOI: $10.1002 /$ tea.21221

Roisman GI, Masten AS, Coatsworth D, Tellegen A. Salient and emerging developmental tasks in the transition to adulthood. Child Development. 75:123-133. DOI: 10.1111/j.1467-8624.2004.00658.x

Rosenberg M. Conceiving the self. New York, NY: Basic Books; 1979.

Schunk DH, Pajares F. Competence perceptions and academic functioning. In: Elliot AJ, Dweck CS, editorsHandbook of competence and motivation. New York: Guilford Press; 2005. 85-104. 
Schwartz SJ, Zamboanga BL, Luyckx K, Meca A, Ritchie RA. Identity in emerging adulthood: Reviewing the field and looking forward. Emerging Adulthood. 2013; 1:96-113. DOI: $10.1177 / 2167696813479781$

Settles IH. When multiple identities interfere: The role of identity centrality. Personality and Social Psychology Bulletin. 2004; 30:487-500. DOI: 10.1177/0146167203261885 [PubMed: 15070477]

Settles IH, Jellison WA, Pratt-Hyatt JS. Identification with multiple social groups: The moderating role of identity change over time among women-scientists. Journal of Research in Personality. 2009; 43:856-867. DOI: 10.1016/j.jrp.2009.04.005

Seymour E, Hewitt NM. Talking about leaving: Why undergraduates leave the sciences. Boulder, CO: Westview Press; 1997.

Steele CM. A threat in the air: How stereotypes shape intellectual identity and performance. American Psychologist. 1997; 52:613-629. DOI: 10.1037/0003-066X.52.6.613 [PubMed: 9174398]

Usher E. Sources of middle school students' self-efficacy in mathematics: A qualitative investigation. American Educational Research Journal. 2009; 46:275-314. DOI: 10.3102/0002831208324517

Vermunt JK. Latent class modeling with covariates: Two improved three-step approaches. Political Analysis. 2010; 18:450-469. DOI: 10.1093/pan/mpq025

Walton GM, Cohen GL. A question of belonging: Race, social fit, and achievement. Journal of Personality and Social Psychology. 2007; 92:82-96. DOI: 10.1037/0022-3514.92.1.82 [PubMed: 17201544]

Waterman AS. Developmental perspectives on identity formation: From adolescence to adulthood. In: Marcia JE, Waterman AS, Matteson DR, Archer SL, Orlofsky JL, editorsEgo identity: A handbook for psychosocial research. New York, NY: Springer-Verlag; 1993. 42-68.

Watt HMG. Development of adolescents' self-perceptions, values, and task perceptions according to gender and domain in $7^{\text {th }}$-through $11^{\text {th }}$-grade Australian students. Child Development. 2004; 75:1556-1574. DOI: 10.1111/j.1467-8624.2004.00757.x [PubMed: 15369531]

Widaman KF, Ferrer E, Conger RD. Factorial invariance with longitudinal structural equation models: Measuring the same construct across time. Child Development Perspectives. 2010; 4:10-18. DOI: 10.1111/j.1750-8606.2009.00110.x [PubMed: 20369028]

Widaman KF, Reise SP. Exploring the measurement invariance of psychological instruments: Applications in the substance use domain. In: Bryant KJ, Windle M, West SG, editorsThe science of prevention: Methodological advances from alcohol and substance abuse research. Washington, DC: American Psychological Assocation; 1997. 281-324.

Wigfield A, Cambria J. Expectancy-value theory: Retrospective and prospective. In: Urdan TC, Karabenick SA, editorsThe decade ahead: Theoretical perspectives on motivation and achievement. Advances in motivation and achievement. Vol. 16A. Bingley, UK: Emerald Group Publishing Limited; 2010. 35-70.

Wigfield A, Eccles JS. Expectancy-value theory of motivation. Contemporary Educational Psychology. 2000; 25:68-81. [PubMed: 10620382]

Wigfield A, Eccles JS, Yoon KS, Harold RD, Arbreton A, Freedman-Doan C, Blumenfeld PC. Changes in children's competence beliefs and subjective task values across the elementary school years: A three-year study. Journal of Educational Psychology. 1997; 89:451-469.

Wong CA, Eccles JS, Sameroff A. The influence of ethnic discrimination and ethnic identification on African American adolescents' school and socioemotional adjustment. Journal of Personality. 2003; 71:1197-1232. DOI: 10.1111/1467-6494.7106012 [PubMed: 14633063]

Woodcock A, Hernandez PR, Estrada M, Schultz PW. The consequence of chronic stereotype threat: Domain disidentification and abandonment. Journal of Personality and Social Psychology. 2012; 103:635-646. DOI: 10.1037/a0029120 [PubMed: 22746674]

\section{Appendix A: Full List of Scale Items}

\section{Science Identity}

1. I consider myself a science person. 
2. Being involved in science is a key part of who I am.

3. Being someone who is good at science is important to me.

4. Being good in science is an important part of who I am.

\section{Academic Perceived Competence}

1. I'm certain I can master the skills taught in science classes.

2. I'm certain I can figure out how to do the most difficult class work in science.

3. I can do almost all the work in science classes if I don't give up.

4. Even if the work in science is hard, I can learn it.

5. I can do even the hardest work in science if I try.

\section{Science Self-Efficacy}

I am confident that I can...

1. Use technical science skills (use of tools, instruments, and/or techniques).

2. Generate a research question to answer.

3. Figure out what data/observations to collect and how to collect them.

4. Create explanations for the results of the study.

5. Use scientific literature and/or reports to guide research.

6. Develop theories (integrate and coordinate results from multiple studies). 


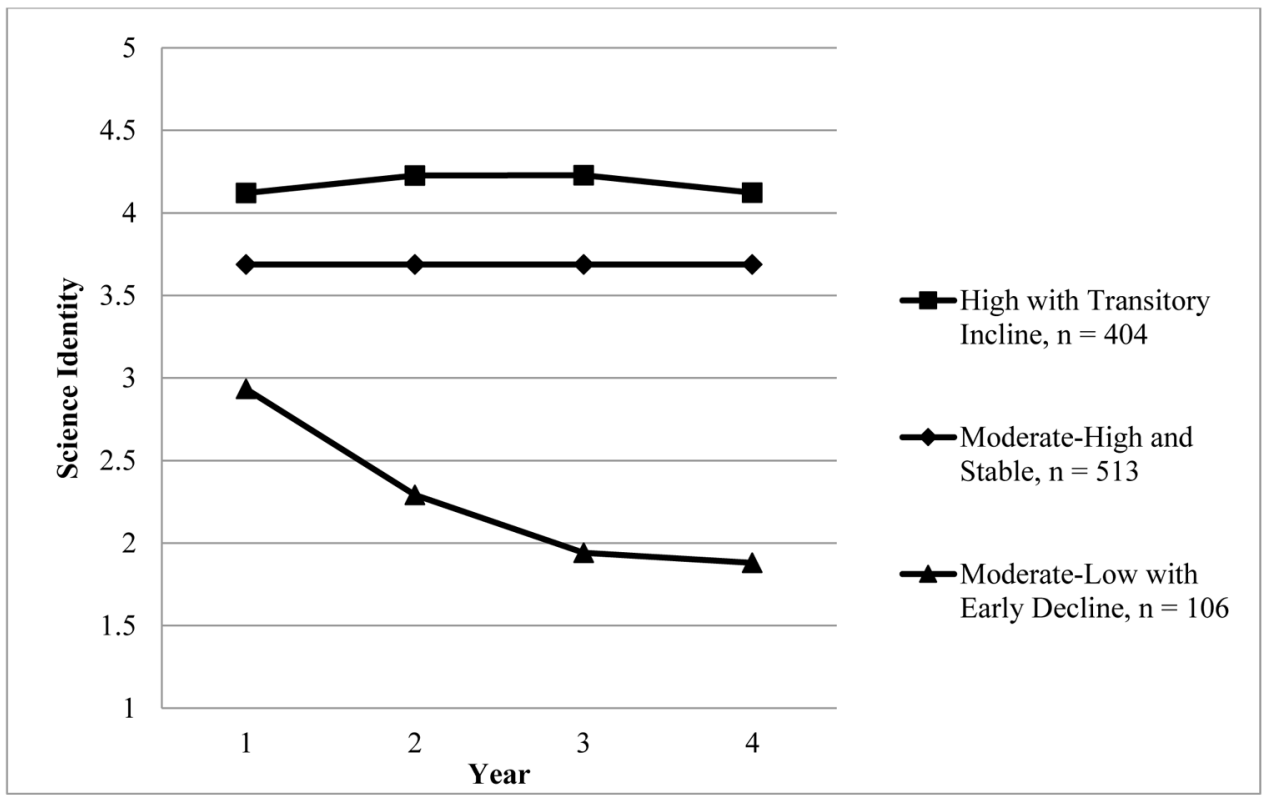

Figure 1.

Model-implied trajectories of science identity for three-class solution over four years. 


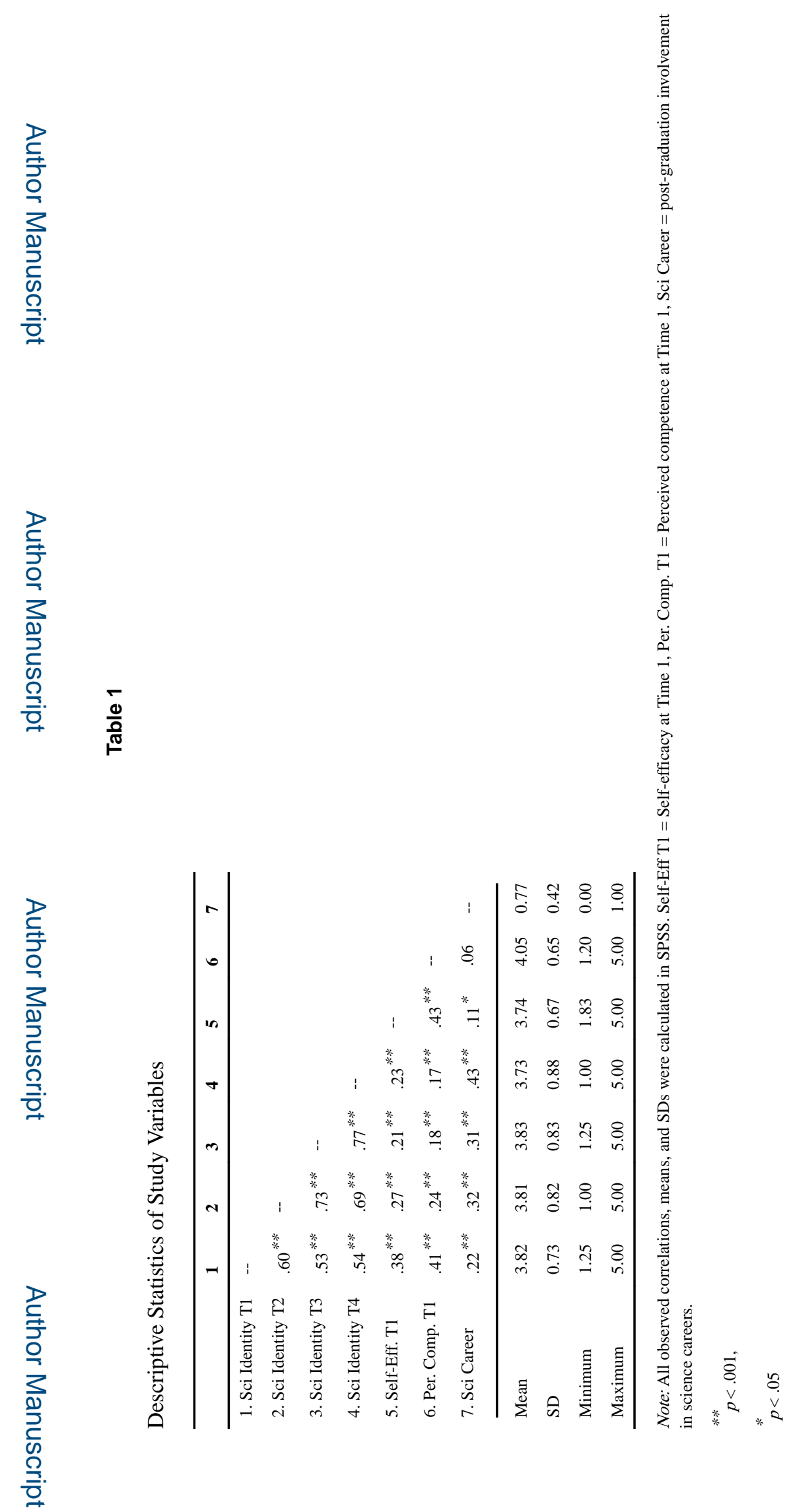

Dev Psychol. Author manuscript; available in PMC 2019 October 01. 

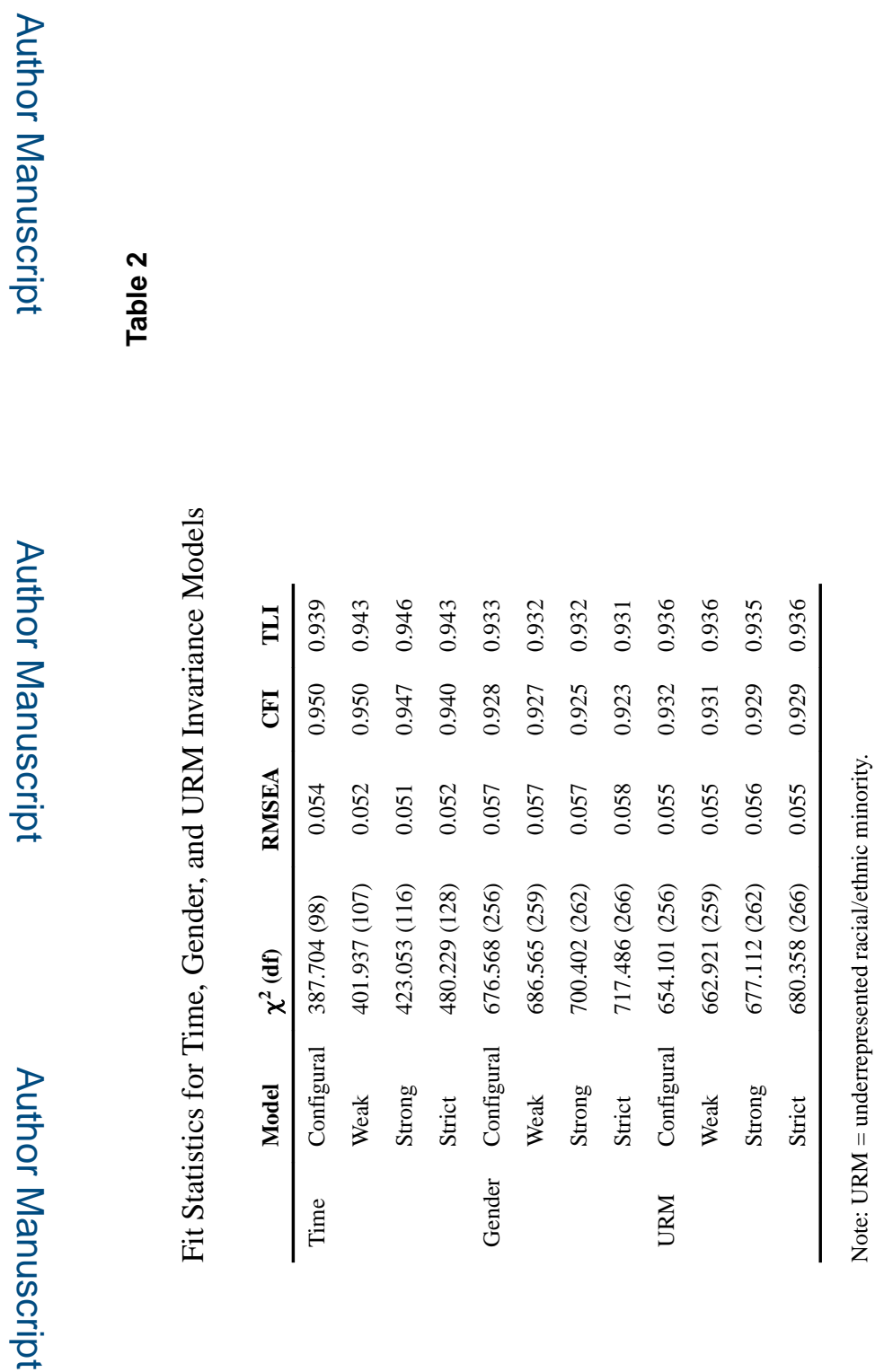

Dev Psychol. Author manuscript; available in PMC 2019 October 01. 


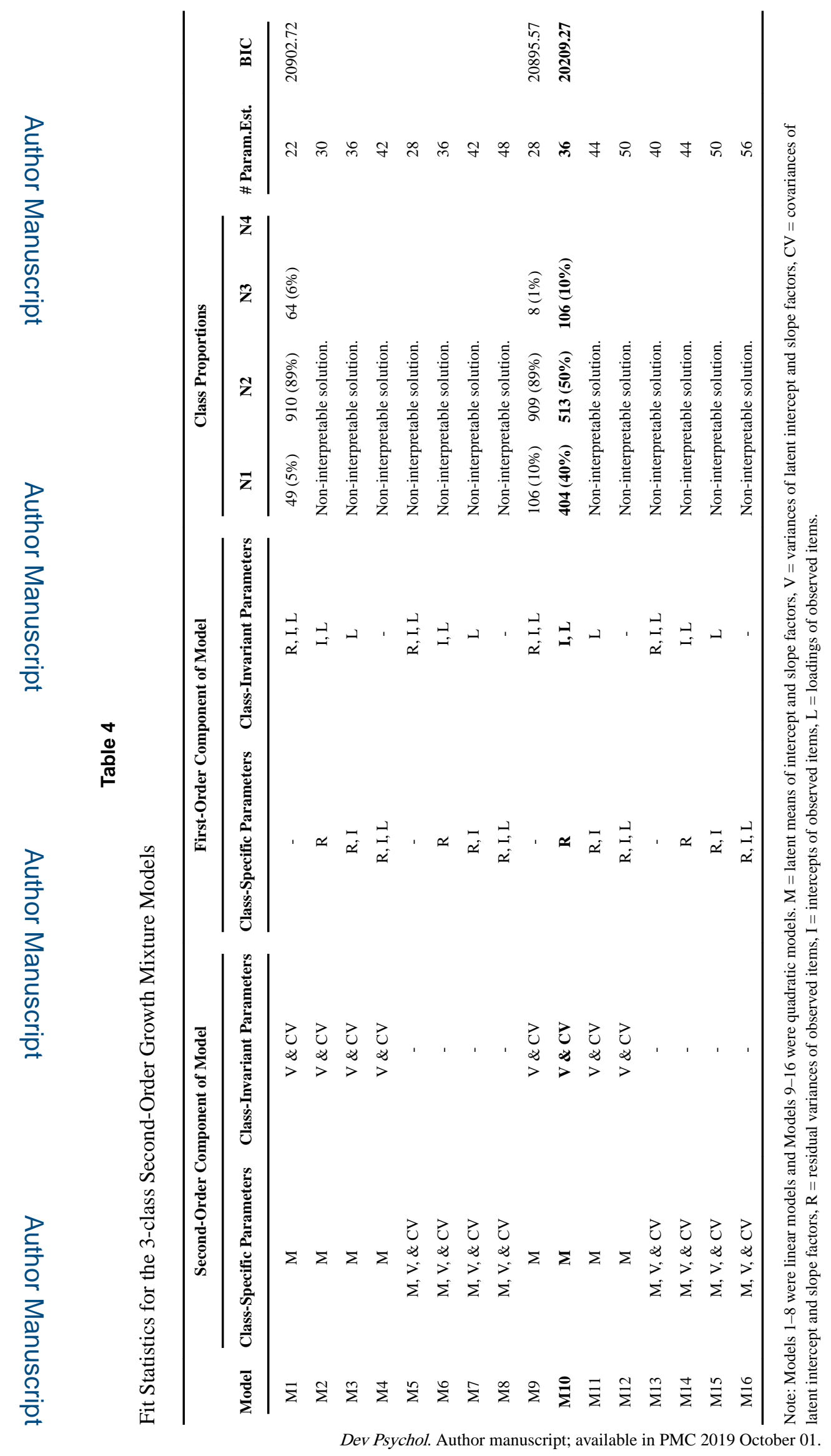


Table 6

Parameter Estimates for Selected 3-class Growth Mixture Model

\begin{tabular}{|c|c|c|c|}
\hline Parameter & Class 1 & Class 2 & Class 3 \\
\hline (n) & 404 & 513 & 106 \\
\hline \multicolumn{4}{|l|}{ Means } \\
\hline Intercept & $4.12^{* * *}$ & $3.61^{* * * *}$ & $2.93^{* * *}$ \\
\hline Linear Slope & $0.16^{* *}$ & 0.04 & $-0.79^{* * *}$ \\
\hline Quadratic Slope & $-0.05^{* *}$ & -0.004 & $0.15^{*}$ \\
\hline \multicolumn{4}{|l|}{ Variances } \\
\hline Intercept & $0.29^{* *}$ & $0.29^{* * *}$ & $0.29^{* * *}$ \\
\hline Linear Slope & $0.19^{* *}$ & $0.19^{* *}$ & $0.19^{* * *}$ \\
\hline Quadratic Slope & $0.01^{*}$ & $0.01^{*}$ & $0.01^{*}$ \\
\hline \multicolumn{4}{|l|}{ Covariances } \\
\hline Intercept, Linear Slope & $-0.11^{* * *}$ & $-0.11^{* * *}$ & $-0.11^{\text {*** }}$ \\
\hline Intercept, Quadratic & $0.02^{*}$ & $0.02 *$ & $0.02 *$ \\
\hline Linear Slope, Quadratic Slope & $0.05^{*}$ & $0.05^{*}$ & $0.05^{*}$ \\
\hline \multicolumn{4}{|l|}{ Note: } \\
\hline \multicolumn{4}{|l|}{${ }^{*} p<.05$} \\
\hline \multicolumn{4}{|l|}{$* * 0.01$} \\
\hline
\end{tabular}

